\title{
Study on the Formation of SiOC Films and the Appropriate Annealing Temperature
}

\author{
Teresa Oh, Member, KIMICS
}

\begin{abstract}
As silicon devices shrink and their density increases, the low dielectric constant materials instead of $\mathrm{SiO}_{2}$ film is required. $\mathrm{SiOC}$ film as low-k films was deposited by the capacitively coupled plasma chemical vapor deposition and then annealed at $300 \sim 500{ }^{\circ} \mathrm{C}$ to find out the properties of the dependence on the temperature and polarity. This study researched the dielectric constant using by the structure of the metal/SiOC film/p-Si, chemical shift, thickness, refractive index and hardness. The trend of reflective index was inverse proportioned the thickness, but the dielectric constant was proportioned it. The dielectric constant decreased with decreasing the thickness and the increment of the refractive index.
\end{abstract}

Index Terms - SiOC film, Dielectric Constant, FTIR.

\section{INTRODUCTION}

IN order to improve the performance of the ultra large scale integration (ULSI), the scaling down have some problems to increase the resistance-capacitance (RC) delay, the signal propagation delay time or cross talk noise between adjacent interconnect lines. Using low-k (low dielectric constant) materials as inter layer dielectric (ILD) instead of $\mathrm{SiO}_{2}$ film is one of these problem's solution [1-4]. SiOC film by the chemical vapor deposition (CVD) is promising ILD materials as low-k materials. Lowing dielectric constant is due to the pores or low polarization. However, it is not clearly defined the reason of the reduction of dielectric constant, and new ultra low-k SiOC film need to satisfy properties of electric, chemical, physical, mechanical and thermal requirements. The formation of SiOC film originates from the reaction of the $\mathrm{C}=\mathrm{O}$ or $\mathrm{C}-\mathrm{O}$ bonds by the plasma dissociation and recombination with many radicals. There are hybrid properties without polarity between hydrophilic and hydrophobic properties in the carbon based system such SiOC film. [5-8]. The SiOC film produced in CVD system consists of limited substitution of $\mathrm{O}$ atoms by the less polarizable $\mathrm{C}$ atoms. The $\mathrm{C}-\mathrm{O}$ group through the phase transition of the $\mathrm{C}=\mathrm{O}$ group participated in the hydrogen bonding is the reasons of low dielectric constant and the chemical shift [9-13]. The SiOC film

\footnotetext{
Manuscript received March 14, 2011; revised March 29, 2011; accepted April 12, 2011.

Teresa Oh is with the Department of Semiconductor, Cheongju University, Cheongju, 360-764, Korea (Email: teresa@cheongju.ac.kr)
}

reduces the dielectric constant by the oxidation process owing to the $\mathrm{H}_{2} \mathrm{O}$ evaporation. However, the function of carbon after annealing can be the origin of the leakage current. Therefore, it is necessary to find out the relationship between the dielectric constant and thermal stability about the electron effect related to the carbon atom after annealing.

The paper was studied on the leakage current and relationship between the dielectric constant and the refractive index.

\section{EXPERIMENTS}

The low-k SiOC films were obtained using the mixed gases of oxygen and trimethylsilane (TMS) by capacitively coupled plasma chemical vapor deposition (CCP-CVD).The chemical properties of SiOC film were researched by Fourier Transform Infrared spectrometer (FTIR, Galaxy 7020A). To obtain the dependence on the temperature of currents, SiOC film was annealed at 300 , 400 and $500{ }^{\circ} \mathrm{C}$, and the leakage current was measured with increasing the substrate temperature at interval of $10{ }^{\circ} \mathrm{C}$ from $20{ }^{\circ} \mathrm{C}$ to $150{ }^{\circ} \mathrm{C}$. To comparison with the refractive index and the leakage current, the refractive index was measured by the Ellipsometer with the source of $632.8 \mathrm{~nm}$. The current-voltage characteristicswere measured using a HP 4155A semiconductor parameter. The dielectric constant was researched from the $\mathrm{C}-\mathrm{V}$ (capacitance-voltage) measurement at $1 \mathrm{MHz}$ using the HP4284A on the MIS ( $\mathrm{Al} / \mathrm{SiOC}$ film/Si substrate) structure.

\section{RESULTS AND DISCUSSION}

In SiOC film with low-k by CVD, the gas precursor is dissociated into ions, cations and radicals which are controlled by the bond dissociated energy. These ions, cations and radicals trend toward more stable bonds than before.

Figure 1(a) explains the FTIR spectra of SiOC film. The main bond in the range of $940 \sim 1500 \mathrm{~cm}^{-1}$ is Si-O$\mathrm{C}$ bond, and the strong peak of $1250 \mathrm{~cm}^{-1}$ is the $\mathrm{Si}-\mathrm{CH}_{3}$ bond. 


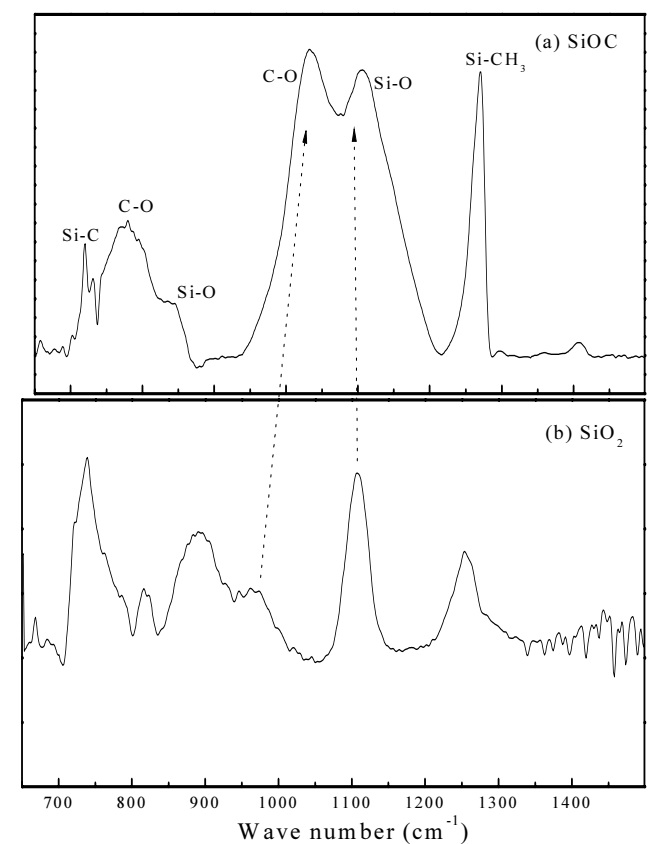

Fig. 1. Comparison of $\mathrm{SiO}_{2}$ and $\mathrm{SiOC}$ films using TMS precursor with the range of $650 \sim 1500$ by using FTIR spectra (a) $\mathrm{SiOC}$ film, (b) $\mathrm{SiO}_{2}$ film.

The low range of $700 \sim 880 \mathrm{~cm}^{-1}$ is related with the union of Si-O, Si-C and C-O bonds, which define the chemical properties of SiOC film. In the narrow band of FTIR spectra under $900 \mathrm{~cm}^{-1}$, the band of $700 \sim 880 \mathrm{~cm}^{-}$ ${ }^{1}$ consists of Si-C, C-O and Si-O bonds. The intensity of these peaks changes as a function of chemical properties of SiOC film. To understand the formation of the bonding structure in SiOC film, it compared with the FTIR spectra of the $\mathrm{SiO}_{2}$ film as shown in Fig. 1(b). The $\mathrm{SiO}_{2}$ film with inorganic properties involves the $\mathrm{Si}-\mathrm{CH}_{3}$ bond of $1250 \mathrm{~cm}^{-1}$, Si-O near $1100 \mathrm{~cm}^{-1}$ and Si-O-C related bond under $1050 \mathrm{~cm}^{-1}$ which shows the strong bond at $740 \mathrm{~cm}^{-1}$ and small bond with $820 \mathrm{~cm}^{-1}$. In comparison with the strong bond at $740 \mathrm{~cm}^{-1}$ in the $\mathrm{SiO}_{2}$ film, SiOC film has the strong peak near $750 \mathrm{~cm}^{-1}$ but the intensity decreases. However, in the range of $700 \sim 880 \mathrm{~cm}^{-1}$, the middle $\mathrm{C}-\mathrm{O}$ bond at $780 \mathrm{~cm}^{-1}$ in SiOC film becomes very strong and broad bond. Moreover, the $\mathrm{Si}-\mathrm{CH}_{3}$ bond of $1250 \mathrm{~cm}^{-1}$ is also very strong and the SiO-C bond of $940 \sim 1200 \mathrm{~cm}^{-1}$ is split two peaks in SiOC film. These characteristic means that the SiOC film becomes organic-inorganic properties owing to the infiltration of carbon atom in Si-O net work mechanism. Finally, the FTIR spectra under $900 \mathrm{~cm}^{-1}$ shortens in spite of the increment of Si-O-C bond observed in FTIR spectra in the range of $940 \sim 1200 \mathrm{~cm}^{-1}$.

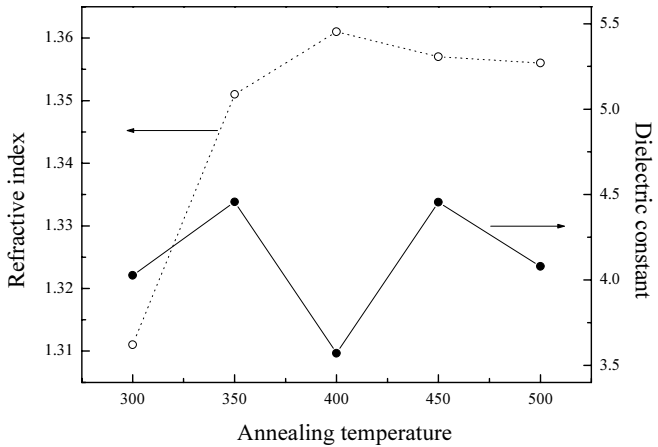

Fig. 2. SiOC film according to the annealing temperature, (a) Refractive index, (b) Dielectric constant.

Figure 2(a) indicates the dielectric constant of $\mathrm{SiOC}$ film using the MIS (metal $/ \mathrm{SiOC}$ film $/ \mathrm{p}-\mathrm{Si}$ ) structure. The dielectric constant changes owing to the annealing temperature. SiOC film annealed at $400{ }^{\circ} \mathrm{C}$ is the lowest dielectric constant.

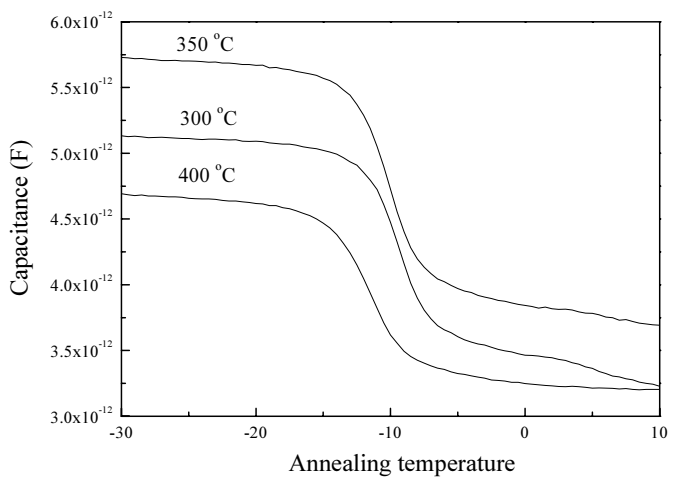

Fig. 3. Capacitance of SiOC film according to the annealing temperature.

Figure 2(b) shows the refractive index of SiOC film at various annealing temperature. The trend of refractive index of $300^{\circ} \mathrm{C}, 350{ }^{\circ} \mathrm{C}$ and $400{ }^{\circ} \mathrm{C}$ increases, but that of $450{ }^{\circ} \mathrm{C}$ and $500{ }^{\circ} \mathrm{C}$ decreases. SiOC film annealed at $400{ }^{\circ} \mathrm{C}$ is the highest refractive index.

Figure 3 presents the capacitance according to various annealing temperature in $\mathrm{SiOC}$ film. The dielectric constant measured using the MIS structure directly depends on the capacitance or thickness. The capacitance is the lowest at sample annealed at $400{ }^{\circ} \mathrm{C}$, and the dielectric constant is also the lowest at this sample as shown in the Fig. 2(a).

Figure 4 is the thickness of annealed SiOC film. The thickness decreases with increasing the annealing temperatures. The effect of annealing process can be obtained from the research about the variation due to the oxidation. The $\mathrm{OH}$ bonds disappear after annealing 
at high temperature. Two $\mathrm{OH}$ bonds in $\mathrm{R}-\mathrm{OH}, \mathrm{Si}-\mathrm{OH}$, $\mathrm{CH}$ or $\mathrm{OH}$ bonds react with each others and $\mathrm{H}_{2} \mathrm{O}$ evaporates.

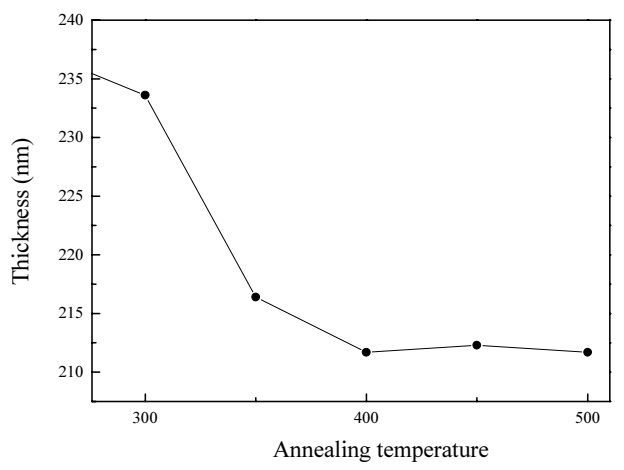

Fig. 4. Thickness of SiOC film according to the annealing temperature.

These sites generate the R-O-R or Si-O-Si cross-link form the oxidation reaction as given by the following equation (1) (5).

$$
\begin{aligned}
& \mathrm{R}-\mathrm{OH}+\mathrm{R}-\mathrm{OH} \rightarrow \mathrm{H}_{2} \mathrm{O} \uparrow+\mathrm{R}-\mathrm{O}-\mathrm{R}(1) \\
& \mathrm{CH}+\mathrm{OH} \rightarrow \mathrm{H}_{2} \mathrm{O} \uparrow+\mathrm{C}(2) \\
& \mathrm{Si}-\mathrm{OH}+\mathrm{Si}-\mathrm{OH} \rightarrow \mathrm{H}_{2} \mathrm{O} \uparrow+\mathrm{Si}-\mathrm{O}-\mathrm{Si}(3) \\
& \mathrm{OH}+\mathrm{OH} \rightarrow \mathrm{H}_{2} \mathrm{O} \uparrow+\mathrm{O}(4) \\
& \mathrm{CH}+5 \mathrm{OH} \rightarrow 3 \mathrm{H}_{2} \mathrm{O} \uparrow+\mathrm{CO}_{2}(5)
\end{aligned}
$$

In view of the progress of reaction, the reaction of the equation of (1) and (2) occurs at lower temperature than that of the equation of (3) (4), because the bond dissociated energy of $\mathrm{CH}$ bond or R-O-R group is lower than that of $\mathrm{OH}$ or Si-OH bonds. That is, there are many carbon or alkyl group obtained by the low annealing temperature. The alkyl group or carbon has many electrons, and can be the source of the leakage current. On the other hand, the high annealing temperature generates the $\mathrm{Si}-\mathrm{O}-\mathrm{Si}$ bonds or oxygen atoms as given by the equation of (3) and (4). The Si-O-Si bond with few carbons make the fine cross link structure without the space effect in the film and finally decreases the thickness. Therefore, it is necessary to do the high annealing process for low-k SiOC film.

\section{CONCLUSIONS}

The SiOC film was prepared with the mixed precursor of TMS and oxygen by the capacitively coupled plasma chemical vapor deposition. The lowest dielectric constant was obtained at the annealed film at $400{ }^{\circ} \mathrm{C}$ and the leakage current at this film was also decreased with increasing the substrate temperature. The thickness decreased in accordance with the increasing of the annealing temperature. But the refractive index increased with increasing the annealing temperature.

\section{REFERENCES}

[1] M. J. Kellicutt, I. S. Suzuki, C. R. Burr, M. Suzuki, M. Ohashi and M. S. Whittingham, "Variable-range-hopping conduction and the Pool-Frankel effect in a copper polyaniline vermiculite intercalation compound," Physical Review B. vol. 47, No. 20, pp.13664-13673, 1993, May.

[2] P. W. May, S. Hohn, W. N, Wang and N. A. Fox, "Field emission conduction mechanisms in chemical vapor deposited diamond and diamondlike carbon films," Appl. Phys. Lett. vol.27, pp. 2182-2184, 1998.

[3] D. J. Gundlach, Y. Y. Lin, T. N. Jackson, S. F. Nelson and D. G. Schlom, "Pentacene Organic Thin-Film Transistors-Molecular Ordering and Mobility, " IEEE ELECTRON DEVICE LETTERS, $18,(1997) 87-89$.

[4] D. J. Gundlach, Y. Y. Lin, T. N. Jackson, S. F. Nelson and D. G. Schlom, "Pentacene Organic Thin-Film Transistors-Molecular Ordering and Mobility, " IEEE ELECTRON DEVICE LETTERS, 18 , (1997) 87-89.

[5] A. Grill and D. A. Neumayer, "Structure of low dielectric constant to extreme low dielectric constant SIOCH films: Fourier transform infrared spectroscopy characterization," J. Appl. Phys. Vol. 94, pp. 6697-6707, 2003

[6] Ioannis Kymissis, C. D. Dimitrakopoulos and Sampath Purushothaman, "High-Performance Bottom Electrode Organic Thin-Film Transistors," IEEE TRANSACTIONS ON ELECTRON DEVICES, Vol.48, pp.1060-1064, 2001.

[7] A. Grill and D. A. Neumayer, "Structure of low dielectric constant to extreme low dielectric constant SIOCH films: Fourier transform infrared spectroscopy characterization," J. Appl. Phys. Vol. 94, pp. 6697-6707, 2003

[8] J. Frenkel, "On pre-breakdown phenomena in insulators and electronic semiconductors," Phys. Rev. 54, pp. 647-648, 1938.

[9] P. R. Emtage and W. Tantraporn, "Schottky emission through thin inslulating films," Physical Review letters, Vol. 8, No. 7, pp. 267$268,1962$.

[10] J. G. Simmons, "Pools-Frenkel Effect and Schottky in MetalInsuloror-Metal Systems," Physial Review, vol. 155, pp. 657-660, 1967.

[11] T. Oh, "Organic Thin Film Transistors Using Pentacene and SiOC film," IEEE transactions on Nanotechnology, 5(2006) 23-29.

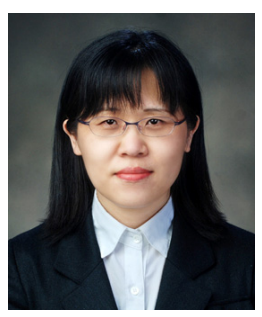

Teresa Oh obtained M.S. and Ph.D. majoring in Electronic Engineering and Communication Engineering at Jeju National University, South Korea, in 1996 and 2000 respectively. She has been a professor in Department of Semiconductor Engineering at Cheongju University since 2005. She worked as a researching professor in Department of Ceramic Eng. at Changwon National University in 2005. Aug., Her research field includes dielectric materials, organic TFT or materials for solar cell. 